\title{
The Challenge of Return-To-Play Decision after Anterior Cruciate Ligament Reconstruction
}

\section{François Delvaux, Jean-Louis Croisier and Jean-François Kaux*}

Department of Sport and Rehabilitation Sciences, University and CHU of Liege, Belgium

The anterior cruciate ligament (ACL) injury is the sport-related injury that generates the largest amount of scientific studies. By simply searching for the keywords « anterior cruciate ligament » on Pubmed, about 15000 results appear, with more than 1200 in 2015 alone. The important sports, medical and economic consequences of such an injury could justify this scientific enthusiasm. In these studies, there is a large variety of topics: epidemiologic data in specific populations, comparisons of different types of surgery or rehabilitation..

One of the thematics that has been gaining popularity is injury prevention. We know that the implementation of preventative programs including strength training, flexibility or neuromuscular balance training is able to significantly reduce the incidence of ACL injury in specific populations such as young female soccer players [1]. "Sportsmetrics", "FIFA 11+ injury prevention program", "Prevent injury and Enhance Performance" are now regularly implemented in the training programs of athletes across the world.

Despite these progresses, some athletes still suffer ACL tears and need surgery with subsequent rehabilitation. As soon as the diagnosis is certain, the athlete and his entourage ask the physician in order to know when he will be able to do sport again. The answer is mostly vague and is generally accompanied by an explanation about the individual variability of recovery after such an injury. Indeed, many parameters influence the period between the surgery and the return-to-play (RTP): the therapeutic choices, the quality of healing and rehabilitation, the possible development of associated pathologies (such as patellofemoral pain syndrome) during the rehabilitation, the patient's motivation, ... When the decision to allow the player to return to play after an ACL reconstruction needs to be made, it is necessary to keep in mind that 6 to $25 \%$ of patients who underwent an ACL reconstruction will suffer another subsequent ACL injury [2-4] This represents a higher injury risk than healthy subjects and consequently, the RTP decision appears crucial with the goal of avoiding re-injury. Additionally, a "time-based criteria", when the physician only respects a theoretical period of sport unavailability, might contribute to allowing athletes back onto the field when they are not physically and/or mentally ready : this approach could possibly increases the risk of re-injury which is associated with more severe consequences than the first episode.

Over and above clinical examination of antero-posterior knee laxity and flexion-extension ranges of motion, it appears necessary to use objective and subjective criteria that will help the physician to assess with more precision the athlete's ability for sport participation. The objective criteria are mainly composed of physical performance assessments: quadriceps and hamstrings isokinetic muscle strength, one-leg hop tests, balance control assessment, jump biomechanics, or a specific sport test. On the subjective side, some questionaires are available such as the ACL-RSI (Anterior Cruciate Ligament - Return to Sport after Injury) which is a scale for measuring the psychological impact of returning to sport after ACL reconstruction [5].

However, the use of a battery of criteria gives rise to many questions: which type of assessment tool should we use? Which assessment parameters should we take into consideration? What level of results is objectively associated with an optimal healing? Are there limitvalues for which the risk of re-injury is significantly increased, strongly recommending to delay RTP? Do these limit-values vary according to the type of sport or the level of the athlete? Despite the impressive amount of studies about ACL, it is actually difficult to answer these questions due to the lack of scientific evidence [6].

Whatever the type of injury, some authors proposed guidelines or suggestions to help clinicians make an informed decision as to whether an injured athlete may safely return to practice and/or competition. For example, a model developed by Creighton could clarify the processes that clinicians have to apply when making their decisions [7].

Finally, instead of talking about return-to-play or return to sport, it might be more relevant to talk about return to performance. This slight difference of semantics should imply that an athlete has to successfully fulfill specific criteria before RTP. The risk of subsequent re-injury, even if it cannot be totally erased, would be reduced to the bare minimum.

\section{References}

1. Kaux JF, Delvaux F, Forthomme B, Crielaard JM, Croisier JL (2013) The risk factors for the reupture of the anterior cruciate ligament of the knee: the neuromuscular state. OA Sports Medicine 1: 9

2. Paterno MV, Rauh MJ, Schmitt LC, Ford KR, Hewett TE (2012) Incidence of contralateral and ipsilateral anterior cruciate ligament $(A C L)$ injury after primary ACL reconstruction and return to sport. Clin J Sport Med 22: 116-121.

3. Salmon L, Russell V, Musgrove T, Pinczewski L, Refshauge K (2005) Incidence and risk factors for graft rupture and contralateral rupture after anterior cruciate ligament reconstruction. Arthroscopy 21: 948-957.

4. Wright RW, Dunn WR, Amendola A, Andrish JT, Bergfeld J, et al. (2007) Risk of tearing the intact anterior cruciate ligament in the contralateral knee and rupturing the anterior cruciate ligament graft during the first 2 years after anterior cruciate ligament reconstruction: a prospective MOON cohort study. Am J Sports Med 35: 1131-1134.

5. Webster KE, Feller JA, Lambros C (2008) Development and preliminary validation of a scale to measure the psychological impact of returning to sport following anterior cruciate ligament reconstruction surgery. Phys Ther Sport 9 : 9-15.

6. Delvaux F, Rochcongar P, Bruyère O, Bourlet G, Daniel C (2015) Return-toplay criteria after ACL reconstruction: actual medicine practice in professional soccer teams (French). Sci Sports 30: 33-40.

7. Creighton DW, Shrier I, Shultz R, Meeuwisse WH, Matheson GO (2010) Return-to-play in sport: a decision-based model. Clin J Sport Med 20: 379-385.

${ }^{*}$ Corresponding author: Kaux JF, Department of Sport and Rehabilitation Sciences, University and CHU of Liege, Belgium, Tel: 32436684 73/82 41; E-mail: jfkaux@chu.ulg.ac.be

Received December 24, 2015; Accepted December 28, 2015; Published December 30, 2015

Citation: Delvaux F, Croisier JL, Kaux JF (2015) The Challenge of Return-To-Play Decision after Anterior Cruciate Ligament Reconstruction. J Pain Relief 4: e120. doi:10.4172/2187-0846.1000e120

Copyright: (C) 2015 Delvaux F, et al. This is an open-access article distributed unde the terms of the Creative Commons Attribution License, which permits unrestricted use, distribution, and reproduction in any medium, provided the original author and source are credited. 